\title{
Evacuation of people to a medium-high public buildings
}

\author{
Marcin Cisek $^{1}$, Kamil Ciszewski ${ }^{1}$ and Robert Piec $^{1, *}$ \\ ${ }^{1}$ The Main School of Fire Service, Faculty of Fire Safety Engineering, 52/54 Slowackiego St., 01-629 \\ Warsaw, Poland
}

\begin{abstract}
Evacuation of people into the building that is not classified as dedicated protective one is not a conventional solution. However, the experiment described in the study shows that with the appropriate identification of a threat and proper alerting this type of evacuation can be an effective way to preserve the health and lives of people at risk. Examination of the possibility of using a medium-high public building for this purpose is the subject of this study. The study focuses on the verification of potentially safe building areas that can be used to save people, as well as traffic conditions and capacity in these spaces. A research experiment was carried out with use of computer simulation in the Pathfinder software. For the purpose of this study, the possibility of staying in a area relatively easily accessible in buildings was considered. Places generally intended for possible stay of people were: staircases and underground garages. The conducted experiment showed that it is possible to quickly evacuate people into the buildings in case of specific danger occurring. Simulations confirmed that in less than 12 minutes it is possible to evacuate over 500 people from outside to empty spaces such as staircase or a garage of a nearby building.
\end{abstract}

\section{Introduction}

On the night of December 3, 1984, in Bhopal, India, the cloud of deadly gas began to spread in the city where almost a million people lived. Earlier, 43 tons of methyl isocyanate (MIC) were released in the nearby plant. This substance, in the form of white mist, spreading through the streets, eventually caused one of the most tragic disasters in the history of mankind. As a result, 20000 people died, of which about 3000 were directly at the scene. About 500000 people have been affected to varying degrees. It is not possible to completely eliminate the threats of anthropogenic and natural disasters. In this context, it is crucial to ensure people's security of proper preparation and response understood as crisis management phases [1]. According to reports from the New York Times [2], in an industrial plant where there was a breakdown, buses for population evacuation were prepared. Panicked employees did not attempt to use them. However, the question remains: how to evacuate a city of almost a million inhabitants with the help of buses during a few or several dozen minutes?

\footnotetext{
*Corresponding author: rpiec@sgsp.edu.pl
} 
While analyzing the course of the incident, one may conclude that the classic evacuation of endangered people due to the number of people at risk was not possible in a sufficiently short time. The only chance for people was the ability to quickly hide from the deadly substance. Methyl isocyanate is a substance whose highest concentration of toxic substance is near the ground [3]. Thousands of people could have a chance to survive on the conditions that:

- they had been warned early,

- and evacuation had been organized towards the interior of buildings located in the city, on their higher floors.

Evacuation of people into a building that is not classified as dedicated protective buildings is not a conventional solution. However, the described example shows that with proper identification of a threat and proper alerting, it can be an effective way to preserve the health and lives of endangered people. Examination of the possibility of using a medium-high (12 to $25 \mathrm{~m}$ high according to Polish law) public building for this purpose is the subject of this study.

The study focuses on the verification of potentially safe building areas that can be used to save people, as well as traffic conditions and capacity in these spaces. A research experiment was carried out with use of computer evacuation simulation in the Pathfinder software. Pathfinder software allows to calculate the time needed to evacuate people from a given space.

For the purpose of this study, the possibility of staying in a area relatively easily accessible in buildings was considered. Places generally intended for possible stay of people are: staircases and underground garages.

The problem appearing in this situation is the gathering of people in an area in a quantity that is not provided for in the design assumptions. In further calculations, the present work focuses on the aspect of the number of people in terms of ensuring their freedom of movement, i.e. entering to a given area of a group of people which need to wait, to survive the threat of outside the building.

Calculations of ambient air temperature rise and ventilation requirements were not taken into account. Only the theoretical number of people that could fit into a given safe space was shown.

\section{Methodology and adopted exercise assumptions}

A variation - controlling behavior model was used for the simulation.

Table 1. Description of geometric models.

\begin{tabular}{|l|l|}
\hline Geometric model & $\begin{array}{l}\text { Navigation surfaces in a geometric } \\
\text { model }\end{array}$ \\
\hline Model 1 & Staircase + external area \\
\hline Model 2 & Same as Model 1 + underground garage \\
\hline Model 3 & Same as model 1 \\
\hline
\end{tabular}

The area of the staircase was $168 \mathrm{~m}^{2}$, and the vestibule was $10.8 \mathrm{~m}^{2}$. Model 1 has 8 floors and 7 inter-story landings in the staircase. The doors used in the models have a width of $1.2 \mathrm{~m}$. The stairs have a width of $1.2 \mathrm{~m}$. These dimensions reflect the parameters of one of the existing buildings in Poland. The speeds that were used in the simulations are given in Table 2. 
Table 2. Speeds of agents used in simulations [4].

\begin{tabular}{|c|c|c|}
\hline \multicolumn{3}{|c|}{ The speed of human models used in simulation } \\
\hline & $\begin{array}{c}\text { The minimum speed } \\
{[\mathbf{m} / \mathbf{s}]}\end{array}$ & Maximum speed $[\mathbf{m} / \mathbf{s}]$ \\
\hline Men & 1.1 & 1.6 \\
\hline Women & 1.05 & 1.45 \\
\hline $\begin{array}{c}\text { Children under 14 years of } \\
\text { age }\end{array}$ & 0.71 & 1.25 \\
\hline Seniors & 0.57 & 1.02 \\
\hline
\end{tabular}

For elders, for the needs of this study, speed was accepted as for people with movement disability. Speed for children under 14 years of age was accepted as for people with disabilities.

Shoulder width of agents is shown in table number 3.

Table 3. Widths of the shoulders of the agents used in the study [4].

\begin{tabular}{|c|c|c|}
\hline & $\begin{array}{c}\text { Minimal shoulder width } \\
{[\mathbf{c m}]}\end{array}$ & $\begin{array}{c}\text { Maximum shoulder width } \\
{[\mathbf{c m}]}\end{array}$ \\
\hline Men & 40.64 & 49.23 \\
\hline Women & 35.56 & 44.96 \\
\hline $\begin{array}{c}\text { Children under 14 years } \\
\text { of age }\end{array}$ & 24.13 & 46.23 \\
\hline Seniors & 36.58 & 49.28 \\
\hline
\end{tabular}

"Profile" is a term introduced by the Pathfinder software. It defines the dimensions and speed of a given group of agents and it must be filled in personally (since the default values are the same for all profiles). The discrepancy in the width of children's shoulders results from the adoption of a minimum width as for three-year-olds and maximum as for fifteenyear-olds. It was assumed that a fourteen-year-old child does not differ much in the width of the arms from a fifteen-year-old child. The dimensions of people collected by the Central Statistical Office in Poland are systematized for children up to 14 years of age, and in the American study [4] research is conducted for children aged 15 years. The width of the shoulders in the case of seniors is also given in wide range, because in one profile there are both women and men. The height of people used in the experiment:

- Men $1.65-1.95 \mathrm{~m}$,

- Women $1.55-1.8 \mathrm{~m}$,

- Seniors 1.5-1.8 m,

- Children 0.9-1.5 m.

An important parameter in this research is people density outside building. It defines frequency of people arriving the building entrance door. To determine this density the attendance data from 2015 year from Piotrkowska Street, Łódź [5] was used. The street length is about $4200 \mathrm{~m}$ [6], and the average width is $20 \mathrm{~m}$ (narrowest point $-16 \mathrm{~m}$, widest point $-24 \mathrm{~m}$ ) [7]. In the result there is about $84000 \mathrm{~m}^{2}$ area. Considering, that after $6 \mathrm{pm}$ during Fridays and Saturdays there are average 20000 people [8] in this area, hence the assumed people density on the street is as follows -20000 people $/ 84000 \mathrm{~m}^{2}=0.238$ $\operatorname{person} / \mathrm{m}^{2}$.

Hours after $6 \mathrm{pm}$ are selected, because an conservative situation was considered. Constant density outside the building was used with value 0.24 person $/ \mathrm{m}^{2}$. 
Table 5. Simulation variants.

\begin{tabular}{|c|c|c|}
\hline Variants of simulation & Geometric model & Description \\
\hline Variant 1 & Model 1 & $\begin{array}{l}\text { Evacuation to the } \\
\text { staircase }\end{array}$ \\
\hline Variant 2 & Model 2 & $\begin{array}{l}\text { Evacuation to the } \\
\text { underground garage }\end{array}$ \\
\hline Variant 3 & Model 3 & $\begin{array}{l}\text { Evacuation from the } \\
\text { staircase to the outside }\end{array}$ \\
\hline
\end{tabular}

For each variant, the simulation was carried out 5 times, so as to check the results convergence. In each of the four additional tests (one basic and four checking), the agents locations were changed and the agent profiles were randomly set.

\section{Simulation results and their analysis}

Summarizing the five simulations of variant No. 1 using the geometric model No. 1, the following results were obtained: on average, 531 people entered the building, in 687 seconds; 490 people entered the staircase, during 685 seconds; by converting the result to minutes, 687 seconds were obtained $=11$ minutes and 27 seconds, 685 seconds $=11$ minutes and 25 minutes.

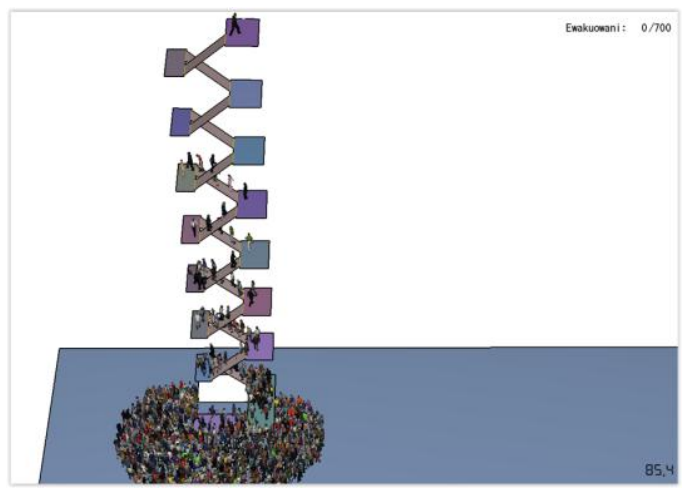

Fig. 1. Evacuation to the staircase.

In variant 2 , using the geometric model No. 2, the evacuation time to the garage was on average 875.8 seconds. The evacuation time to the garage of 531 people is on average 677 seconds. There is a very similar result as in the case of evacuation to the staircase. A very important advantage of the garage over the staircase is its 2.5 times larger area. 


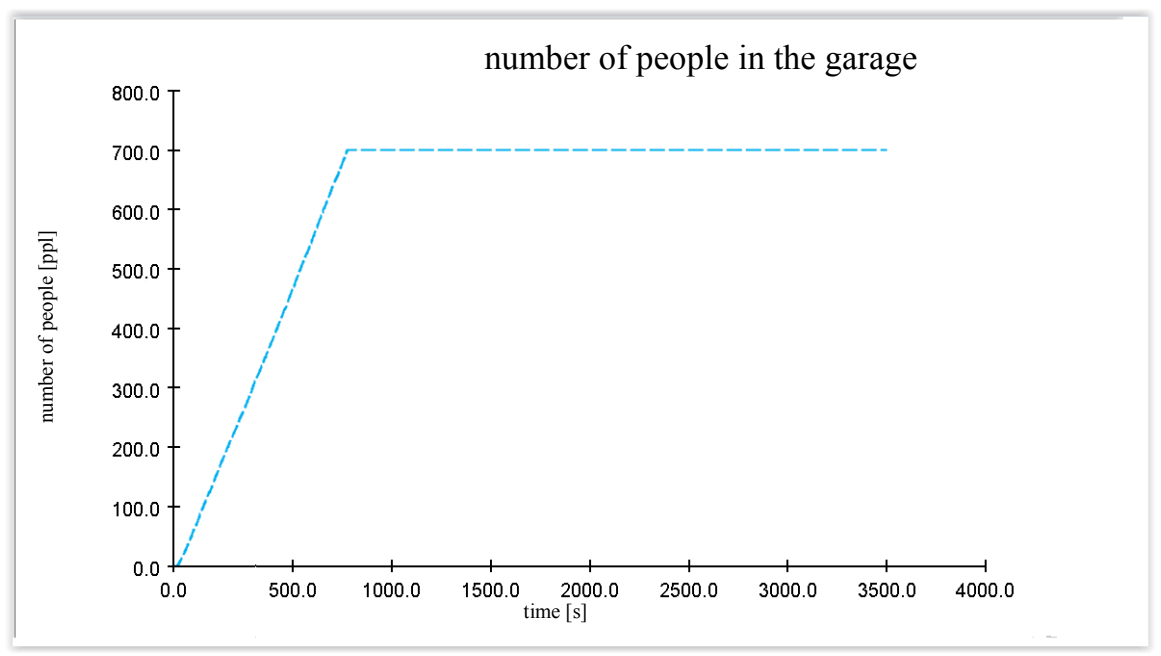

Fig. 2. Number of people in the garage as a function of time.

In simulation of variant 3 using geometric model No. 3, the average evacuation time to outside is the 531 agents (human models) from the staircase was approx. 544.6 seconds, and the average evacuation time from the entire building was 550.4 seconds. Converting seconds to minutes: $544.6 \mathrm{~s}=9$ minutes and 4.6 seconds, and 550.4 seconds $=9$ minutes and 10.4 seconds.

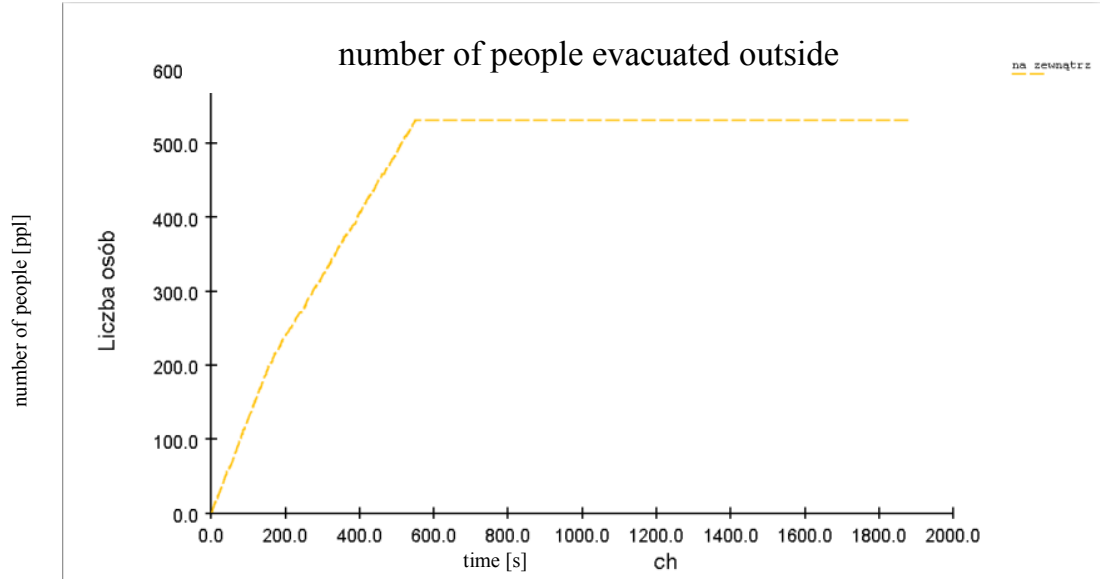

Fig. 3. Number of people leaving the staircase.

\section{Conclusions}

Safe places in the context of temporary shelter against the threat of contaminated atmosphere in most large cities can be found very often. These are usually buildings with both staircases and garages. Mass evacuation is a difficult issue, requiring a very good technical base and proper organization. Evacuation of people into a building whose primary function is not the role of a protective building is now a theoretical concept. However, the conducted experiment showed that it is possible to quickly evacuate people into the buildings in case of specific danger occurring. Simulations confirmed that in less than 12 minutes it is possible to evacuate over 500 people from outside to empty spaces such as staircase or a garage of a nearby building. 
The results of simulation No. 1 indicate that one staircase in an 8 -story building can be used to evacuate 531 people in 687 seconds. For the evacuation of the entire Piotrkowska Street in Łódź, where after 8 p.m. there are 20000 people present, about 40 staircases of similar area are needed.

The simulation shows that up to 1723 people can be evacuated to one underground garage, and thus 12 garages are needed to evacuate Piotrkowska Street.

The number of facilities needed is relatively large, however, it should be noted that these facilities can be relatively easily accessible, especially in large cities. It would be impossible to quickly provide security or shelter for 20000 people on the street in a different way.

In the first variant, people location and density was a very important factor - and their distance from the building. This parameters, for obvious reasons, does not appear in the third variant, which strongly shortens the obtained evacuation time.

The calculated evacuation times for the same number of people (531) are similar. Both for the garage and staircase, this time is about 680 seconds. Stairs were used to get to area of safety in both cases, which slowed down the process of evacuation into the building.

Results of analysis of technical and organizational solutions used in such buildings indicate that there are following obstacles for evacuation from external spaces into the building:

- access control system in many buildings,

- lack of ventilation and sanitary systems in the considered spaces,

- difficulties in evacuation for regular users of the building (stair case can be filled with people)

- difficulties for the rescue services reaching the evacuees caused by large numbers of people gathering in places unsuitable for it.

Results of the conducted simulations have highlighted a certain advantage of the underground garage over the staircase as the place of the target evacuation of people from outside. It was noticed that:

- the garage used in the experiments has bigger area than staircase and it can accommodate more people,

- there can be prepared makeshift medical point which would could be accessed by anyone who needs medical intervention,

- mostly it contains at least 2 independent entrances (through the staircase or garage gate), while staircase has usually only one exit outside,

- there are higher technical requirements for garages (for example stricter requirements for construction and fire protection),

- contains less obstacles than staircases (railings, decorative plasters, steps).

In the context of analyzed problem staircase have also advantages and solutions more convenient than those used in garages:

- height of staircase above ground level. Many commonly used danger substances, cause the greatest threat near ground level, hence the possibility of hiding in the upper parts of the staircase is very important,

- this is much easier to find staircase in the city, than underground garage.

It should be emphasized that currently people evacuation into the building is possible only after proper building preparation for such purpose. It should be then taken into account that there is a possibility of neutralization of hazardous substances in air filters in ventilation systems or a possibility of using closed circuit circulation ventilation. Additionally, when considering that currently in Poland only $2.85 \%$ of whole population, can find place in protective buildings [9], this is a concept worth considering. 


\section{Literature}

1. J. Gołębiewski, Emergency Manager Handbook, (Szkoła Aspirantów Państwowej Straży Pożarnej, Kraków 2003)

2. S. Diamond, The New York Times, 28 (January 1985)

3. Internet database of dangerous substances, Centralny Instytut Ochrony - Państwowy Instytut Badawczy (accessed: 17 February 2018)

4. J.L. Smith, J.T. Brokaw, Agent-Based Simulation of Human Movements During Emergency Evacuations of Facilities (Applied Research Associates, Inc. 2008)

5. M. Witkowska, Dziennik Łódzki 29 (may 2015)

6. https://pl.wikipedia.org/wiki/Ulica_Piotrkowska_w_Łodzi (accessed: 17 February 2018)

7. Geoportal Infrastruktury Informacji Przestrzennej, http://www.geoportal.gov.pl/ (accessed: 17 February 2018)

8. R. Jakubczak, National protection in creating the security of the 3 RP (Bellona, Warszawa 2003)

9. Assessment of preparations in the field of civil protection and civil defense in Poland for 2016, Obrona Cywilna Kraju, www.ock.gov.pl, (accessed: 20 September 2018) 